\title{
Therapy Trial Design in Vanishing White Matter
}

\section{An Expert Consortium Opinion}

Correspondence

Dr. van der Knaap

ms.vanderknaap@vumc.nl

Seyed Ali Fatemi, MD, Nicole I. Wolf, MD, PhD, Elise Saunier-Vivar, PhD, Robert Rauner, Hanka Dekker,

Pieter van Bokhoven, PhD, Peter van de Ven, PhD, and Prisca S. Leferink, PhD

Neurol Genet 2022;8:e657. doi:10.1212/NXG.0000000000000657

\begin{abstract}
Vanishing white matter (VWM) is a leukodystrophy caused by recessive variants in the genes EIF2B1-EIF2B5. It is characterized by chronic neurologic deterioration with superimposed stress-provoked episodes of rapid decline. Disease onset spans from the antenatal period through senescence. Age at onset predicts disease evolution for patients with early onset, whereas disease evolution is unpredictable for later onset; patients with infantile and early childhood onset consistently have severe disease with rapid neurologic decline and often early death, whereas patients with later onset have highly variable disease. VWM is rare, but likely underdiagnosed, particularly in adults. Apart from measures to prevent stressors that could provoke acute deteriorations, only symptomatic care is currently offered. With increased insight into VWM disease mechanisms, opportunities for treatment have emerged. EIF2B1-EIF2B5 encode the 5-subunit eukaryotic initiation factor $2 \mathrm{~B}$ complex, which is essential for translation of mRNAs into proteins and is a principal regulator of the integrated stress response (ISR). ISR deregulation is central to VWM pathology. Targeting components of the ISR has proven beneficial in mutant VWM mouse models, and several drugs are now in clinical development. However, clinical trials in VWM pose considerable challenges: low numbers of known patients with VWM, unpredictable disease course for patients with onset after early childhood, absence of intermediate biomarkers, and novel first-in-human molecular targets. Given these challenges and considering the critical need to offer therapies, we have formulated recommendations for enhanced diagnosis, drug trial setup, and patient selection, based on our expert evaluation of molecular, laboratory, and clinical data.
\end{abstract}




\section{Glossary}

ATF4 = activating transcription factor 4; CHOP $=$ C/EBP homologous protein; DTI $=$ diffusion tensor imaging; eIF2B = eukaryotic initiation factor 2B; ER = endoplasmic reticulum; FDA = Food and Drug Administration; FLAIR = fluid-attenuated inversion recovery; GADD34 = growth arrest and DNA damage protein 34; GSK3 $\beta$ = glycogen synthase kinase 3 $\beta$; ISR = integrated stress response; $\mathbf{m c D E S P O T}=$ multicomponent driven-equilibrium single-pulse observation of T1/T2; MLD = metachromatic leukodystrophy; $\mathbf{M R S}=$ magnetic resonance spectroscopy; $\mathbf{M T R}=$ magnetization transfer ratio; $\mathbf{M W F}=$ myelin water fraction; NODDI = neurite orientation dispersion and density imaging; OMIM = Online Mendelian Inheritance in Men; VWM = vanishing white matter.

Vanishing white matter (VWM), or childhood ataxia with CNS hypomyelination, was recognized in the 1990s (Online Mendelian Inheritance of Men (OMIM) 603896). ${ }^{1-3}$ Initially, VWM was described as an early childhood-onset devastating encephalopathy with chronic deterioration, superimposed episodes of stressprovoked decline, and early fatality. ${ }^{1-3}$ Once the 5 genes associated with VWM were identified, it became apparent that VWM has a pleomorphic natural history, with disease onset ranging from the antenatal period through senescence and an extremely variable disease course ranging from rapid progression and early death to minimal involvement over decades. ${ }^{4}$

Considering the almost exclusive involvement of the CNS white matter in VWM, it was unexpected that the genetic cause resides in the ubiquitously expressed eukaryotic initiation factor $2 \mathrm{~B}$ (eIF2B). ${ }^{5}$ eIF2B is essential for initiation of translation of mRNAs into proteins. ${ }^{6}$ It is also a central regulator of mRNA translation rate and principal component of the integrated stress response (ISR), a molecular pathway responsive to different types of stress. ${ }^{6}$ Deregulated ISR is central to the pathophysiology of VWM, ${ }^{7}$ and ISR modulation can reduce disease severity in VWM mouse models. ${ }^{7-9}$

These insights have opened an exciting new era of potential drug therapies for VWM. However, the constitutive biologic processes involved in VWM pathophysiology ${ }^{6}$ and inherent variability of its natural history ${ }^{4}$ make clinical development of therapies challenging. The need for unbiased assessment of safety, tolerability, and efficacy of several promising drugs is additionally challenged by the low numbers of known patients with VWM. Initiation of simultaneous competing drug trials may limit the ability to assess drug efficacy with sufficient power.

\section{Consortium of Clinical Experts on VWM}

Recognizing these challenges, an international independent consortium of 9 clinician-scientists, expert in VWM, was founded in 2019. ${ }^{10}$ They were selected for clinical and research expertise in leukodystrophies, including VWM, as measured by publications and clinical trials in leukodystrophies, and for geographic representation of countries that follow the International Council for Harmonization-Good Clinical Practice guidelines. Patient and family organizations on leukodystrophies from those countries were invited to form an advisory board. The Industry
Alliance Office of Amsterdam Neuroscience provided expertise on clinician-industry interactions and trial setup.

The mission of the VWM Consortium is to improve patient identification, enable biomarker studies, develop guidelines for clinical trials, and support development of therapeutics. This consensus statement aims to provide evidence-based guidelines for trial design and biomarker considerations to enable and accelerate therapeutic developments and address recruitment challenges.

\section{Background}

\section{VWM Natural History, MRI, and Genetic Etiology}

Recently, an international natural history study described a wide range of phenotypes in 296 patients with VWM. ${ }^{4}$ In $90 \%$ of patients, age at onset is $<18$ years, and in $60 \%$, it is $<4$ years. In $85 \%$, the disease course is chronic with episodic deteriorations; in $15 \%$, it is only chronic. The most common provoking factors are febrile and afebrile infections and head trauma. Rapid neurologic decline is often accompanied by lowered consciousness. As age at onset predicts prognosis in VWM, ${ }^{11} 6$ groups were defined: onset $<12$ months, between 12 and $<24$ months, 2 and $<4$ years, 4 and $<8$ years, 8 and $<18$ years, and $\geq 18$ years. ${ }^{4}$ For onset $<4$ years, the exact age at onset correlates with disease severity, earlier onset being associated with more rapid decline and higher mortality, whereas for onset $\geq 4$ years, the clinical course is generally milder, with a wide variation in severity, not correlating with exact age at onset (Figure 1). Episodic deteriorations are important predictors for more severe disease course (Figure 2), independent of age at onset. ${ }^{4}$

Details per onset category are given in Table 1 . Antenatal or early infantile onset ( $<12$ months) is invariably associated with rapid deterioration and early death. ${ }^{6}$ Patients often display severe generalized encephalopathy with irritability and intractable epilepsy. Involvement of organs outside the CNS is common. ${ }^{4}$ Patients with onset between 12 and $<24$ months show rapid decline with loss of ambulation within months to a few years and early death. ${ }^{6}$ In the classic phenotype, disease manifests between age 2 and 4 years. ${ }^{1-4}$ A stress-provoked episode often marks disease onset. Ataxia and spasticity predominate, whereas cognition is relatively spared. Mild epilepsy is common. Clinical evolution is more variable, but typically associated with early severe disability, even when 

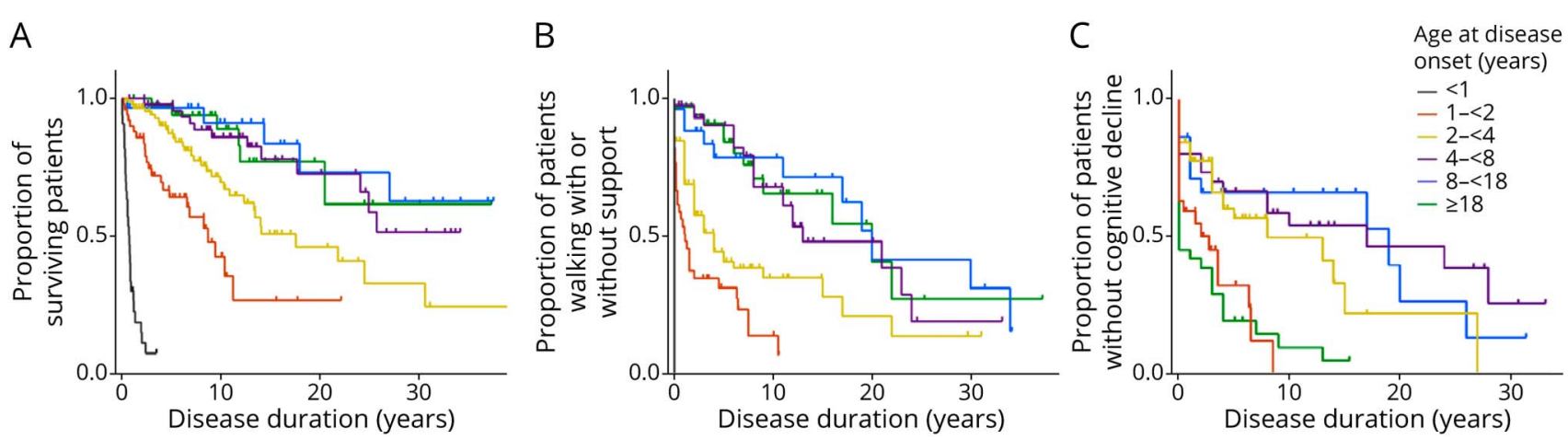

Kaplan-Meier plots for survival (A), walking with or without support (B), and cognition (C) in relation to disease duration, per the age at onset group. In all plots, censored patients (alive at last follow-up, still ambulant, or absence of cognitive decline) are indicated by crosses. Modified from Figure 3, Hamilton et al., Ann Neurol 2018, with permission.

patients reach adulthood. ${ }^{4}$ Onset $\geq 4$ years is associated with extremely variable disease evolution. ${ }^{4}$ Stress-provoked episodic deterioration is less prominent. ${ }^{4}$ Decline is often slow, but sudden deterioration and death may occur. ${ }^{4}$ Patients with adult onset typically present with dementia or psychiatric symptoms and often no or mild motor involvement. ${ }^{4}$ Patients with onset after infancy have exclusive CNS involvement, except for ovarian failure, which is common in females. ${ }^{3,4}$

Brain MRI in affected individuals is often pathognomonic for VWM (Figure 3). ${ }^{3,12}$ T2 signal is increased throughout the cerebral white matter; the directly subcortical white matter may initially be spared. ${ }^{13}$ Fluid-attenuated inversion recovery (FLAIR) images show progressive rarefaction and cystic degeneration of the cerebral white matter. Radiating stripes are present, indicating better preserved white matter tissue strands. ${ }^{12}$ The cerebral white matter abnormalities worsen over time and never reverse. ${ }^{14}$ Cerebellar white matter is normal or less severely affected. ${ }^{12}$ Gray matter structures mostly retain a normal appearance. ${ }^{12}$

MRI features are dependent on age at onset. ${ }^{12,14}$ White matter rarefaction is more rapid with earlier onset. In antenatal or early infantile onset, the cerebral white matter is initially $\mathrm{T} 2$ and FLAIR hyperintense and appears swollen and may disappear completely in a few months. ${ }^{14}$ The cystic white matter may collapse or retain a swollen appearance. ${ }^{14}$ With late infantile or early childhood onset, the cystic white matter may look highly swollen and be associated with increasing macrocephaly. ${ }^{14}$ In adolescents and adults, the abnormalities are often nonspecific. Only the periventricular cerebral white matter may be abnormal, with no or little rarefaction, but with pronounced atrophy. ${ }^{12,14}$

VWM is caused by biallelic pathogenic variants in EIF2B1EIF2B5, encoding the $\alpha-\varepsilon$ subunits of eIF2B., ${ }^{5,12}$ There is

Figure 2 Effect of Stress-Provoked Episodes
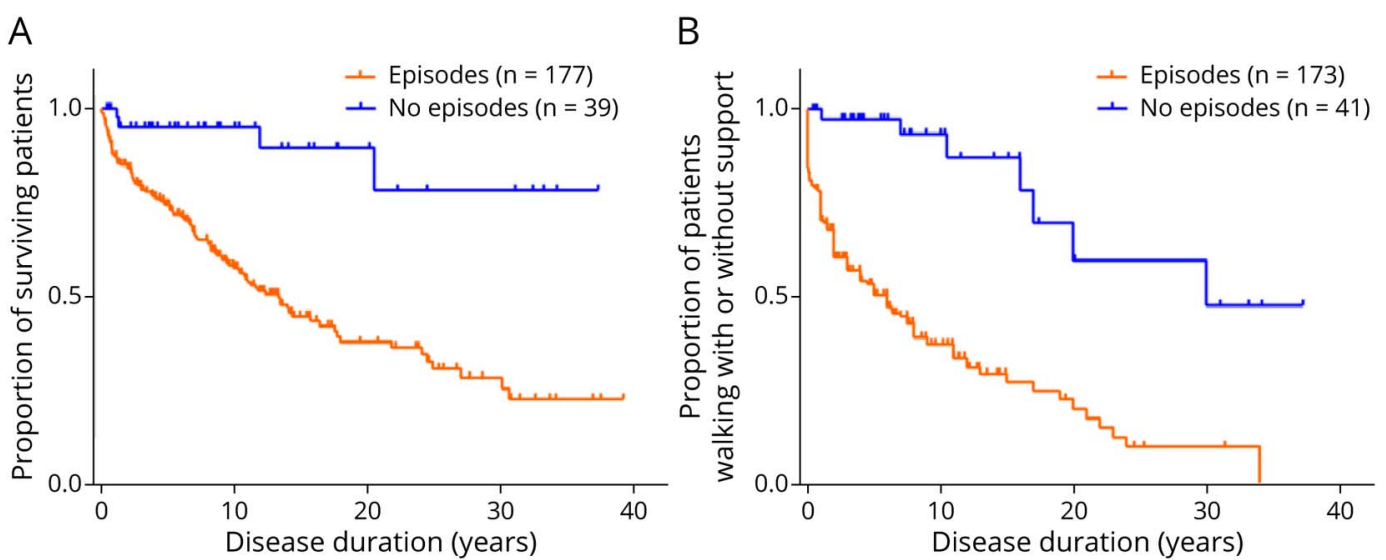

Survival (A) and walking with or without support (B) in relation to disease duration, grouped by disease course with and without episodic deterioration. In all plots, censored patients (alive at last follow-up or still ambulant) are indicated by crosses. Modified from Figure 3, Hamilton et al., Ann Neurol 2018, with permission. 
Table 1 Clinical Characteristics

\begin{tabular}{|c|c|c|c|c|c|c|}
\hline Age at onset groups & $<12$ mo & $1-<2 y$ & $2-<4$ y & $4-<8 y$ & $8-<18 y$ & $\geq 18 y$ \\
\hline Disease onset provoked by trigger & $43 \%$ & $66 \%$ & $72 \%$ & $40 \%$ & $54 \%$ & $21 \%$ \\
\hline Exacerbating disease course & $84 \%$ & $88 \%$ & $93 \%$ & $76 \%$ & $68 \%$ & $59 \%$ \\
\hline Delayed early cognitive development & $63 \%$ & $21 \%$ & $9 \%$ & $9 \%$ & $11 \%$ & $3 \%$ \\
\hline Achieved walking without support & $0 \%$ & $74 \%$ & $100 \%$ & $100 \%$ & $100 \%$ & $100 \%$ \\
\hline Median age of loss of walking without support & n.a. & $2 y$ & $3 y$ & $14 \mathrm{y}$ & $25 y$ & $44 \mathrm{y}$ \\
\hline Median time to loss walking without support ${ }^{a}$ & n.a. & $2 \mathrm{mo}$ & $1 \mathrm{y}$ & $8 y$ & $15 y$ & $7 y$ \\
\hline Median age of full wheelchair dependency & n.a. & $3 y$ & $7 y$ & $18 \mathrm{y}$ & $33 y$ & $56 y$ \\
\hline Median time to full wheelchair dependency ${ }^{a}$ & n.a. & $1 \mathrm{y}$ & $4 y$ & $13 y$ & $20 y$ & $20 y$ \\
\hline Median time to cognitive decline ${ }^{a}$ & n.a. & $2 y$ & $8 y$ & $17 y$ & $19 y$ & $0 y$ \\
\hline Median age of death [quartiles] & $9[6-14] \mathrm{mo}$ & $4[2-8]$ y & $9[6-15]$ y & $13[9-23]$ y & 29 [16-34] y & $37[29-50]$ y \\
\hline Median disease duration at death [quartiles] & $7[3-10] \mathrm{mo}$ & $2[1-6]$ y & $7[3-13]$ y & $6[5-17]$ y & $14[4-22] y$ & $10[4-14] \mathrm{y}$ \\
\hline
\end{tabular}

Abbreviations: $\mathrm{mo}=$ months; n.a. = not applicable; $\mathrm{y}$ = years .

The information in this table is obtained from Hamilton et al., Ann Neurol 2018; 84:274-288.

${ }^{a}$ Calculated from disease onset.

clear genotype-phenotype correlation, with mild and severe variants. ${ }^{411,15,16}$ If a mild and a severe variant are compound heterozygous, disease severity is intermediate. ${ }^{15}$ Although patients with the same variants tend to have a similar disease course, variation may be considerable, especially in onset $\geq 4$ years, even within families. ${ }^{4}$

\section{Disease Mechanisms}

eIF2B is an enzyme with guanine exchange factor activity, required for translation of mRNAs into proteins, ${ }^{17,18}$ and central to regulation of mRNA translation rate by the ISR. ${ }^{19}$ The ISR (Figure 4) is an evolutionarily highly conserved homeostatic pathway, activated by different stressors, including fever, amino acid deprivation, viral infection, heme deficiency, reactive oxygen species, and endoplasmic reticulum (ER) overload with unfolded or misfolded proteins. ${ }^{20}$ Stressors activate kinases, which phosphorylate eIF2. Phosphorylated eIF2 inhibits eIF2B, thereby reducing mRNA translation rate. Inhibition of eIF2B also activates activating transcription factor 4 (ATF4) transcription response, which has numerous downstream effects, including cell survival or apoptosis, cell cycle arrest or proliferation, differentiation, and maturation. ${ }^{20} \mathrm{C} / \mathrm{EBP}$ homologous protein (CHOP), downstream effector of ATF4, is proapoptotic and through a feedback loop sensitizes the ER for further stress. Growth arrest and DNA damage protein 34 (GADD34), downstream effector of CHOP, dephosphorylates eIF2, thereby restoring eIF2B activity and abating the ISR. ${ }^{20}$

VWM pathogenic variants reduce eIF2B activity, ${ }^{21}$ causing constitutive activation of the downstream ISR. Activation of the

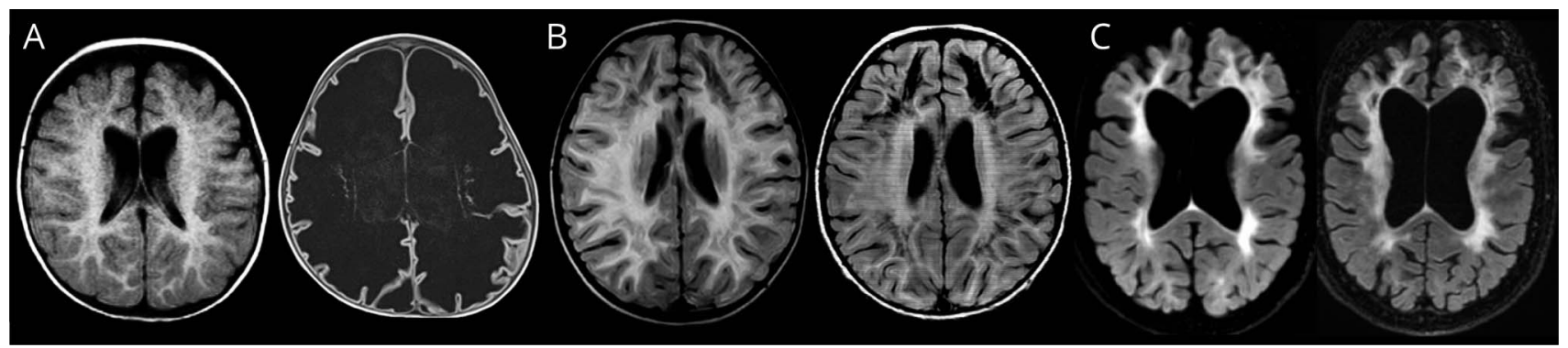

FLAIR images in a patient at clinical presentation at 7 months and follow-up at 24 months (A) show that initially, the cerebral white matter is abnormal but not rarefied, whereas at 24 months, all cerebral white matter has vanished, but still looks swollen. FLAIR images in a patient at clinical presentation at $4 \frac{1}{2}$ years and follow-up at 6 years (B) show abnormal cerebral white matter that is increasingly rarefied and cystic. Note the radiating stripes representing better preserved tissue strands. FLAIR images in a patient at clinical presentation at 48 years and follow-up at 55 years (C) show that the cerebral white matter is abnormal, but the directly subcortical white matter is spared. There are minimal signs of rarefaction, and there is some cerebral atrophy. At follow-up, the atrophy has progressed. 


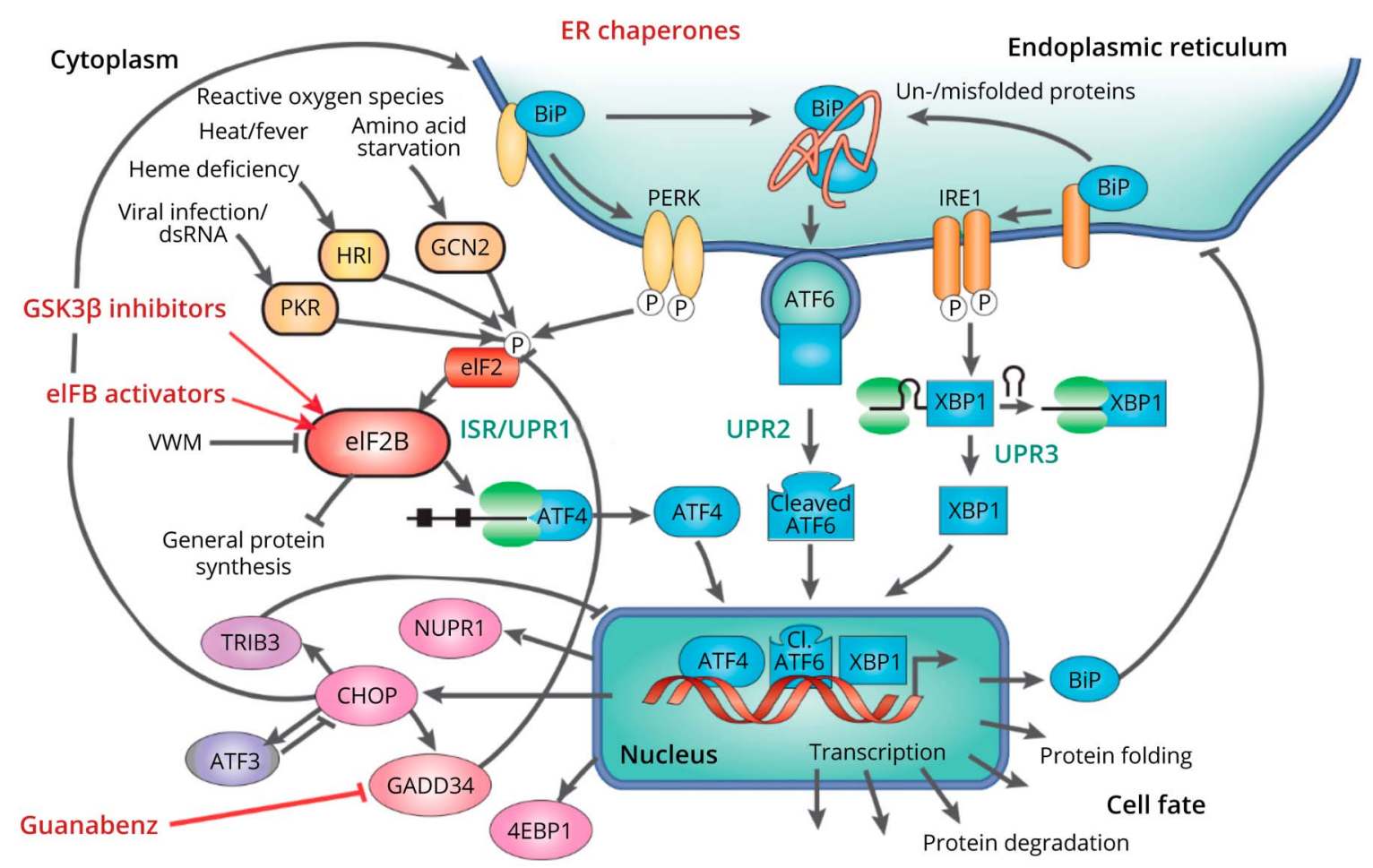

The ISR is activated by 4 kinases (PKR, HRI, GCN2, and PERK), each a sensor for a particular stress type. ER stress activates the unfolded protein response (UPR), which has 3 arms, mediated by PERK, ATF6, and IRE1. The PERK pathway is shared by the ISR and UPR. Activated kinases phosphorylate elF2a, which binds and inhibits elF2B. Pathogenic variants in EIF2B1-EIF2B5 also decrease elF2B activity. Decreased elF2B activity lowers overall mRNA translation and activates the activating transcription factor 4 transcription response, which has major effects on cell fates as cell death, recovery, survival, proliferation, differentiation, and maturation. GADD34 dephosphorylates elF2a, thereby restoring elF2B activity. C/EBP homologous protein sensitizes the ER for stress. elF2B activators stabilize and activate elF2B directly. Glycogen synthase kinase $3 \beta$ inhibitors decrease elF2B phosphorylation, thereby increasing its activity. Guanabenz inhibits GADD34, thereby modulating elF2a phosphorylation and thus elF2B activity. ER chaperones decrease ER stress. Modified from box 1, links.Iww.com/ NXG/A512, Scheper et al., Nat Rev 2007, with permission. elF2B = eukaryotic initiation factor 2B; ER = endoplasmic reticulum; GADD34 = growth arrest and DNA damage protein 34; ISR = integrated stress response; UPR = unfolded protein response.

ATF4 transcription response is observed in VWM mouse and patient brain tissue. ${ }^{7}$ eIF2 phosphorylation is decreased, indicating activation of the GADD34 feedback loop, which is, however, insufficient to restore the downstream ISR to normal. $^{7}$ Activation of conflicting cell fate drivers (proliferation, proapoptosis, and antiapoptosis) is seen in patient brain tissue. ${ }^{22}$ Modulation of the ISR at different levels affects disease severity in VWM mice and patients: ISR stressors, including fever and infections, exacerbate clinical deterioration in patients with VWM and negatively affect outcome (Figure 2), 3,4 whereas drugs enhancing eIF2B activity or modulating the GADD34 feedback loop improve the disease in VWM mice. ${ }^{7-9}$

Deregulated ISR in astrocytes is a key cause of pathology. At autopsy, the cerebral white matter is rarefied and cystic and lacks reactive astrocytes. ${ }^{23}$ Astrocytes have highly abnormal morphology with few, short, thick processes. ${ }^{23}$ Premyelinating oligodendrocyte precursor cells are increased in number, but mature cells are lacking. ${ }^{24}$ Oligodendrocytes and astrocytes fail in their mature functions, including formation and maintenance of myelin and astrogliotic scar, explaining the lack of myelin and cystic white matter degeneration. ${ }^{23,24}$ Coculture studies show that VWM astrocytes inhibit oligodendrocyte maturation and myelination by secreted factors, whereas VWM oligodendrocytes do not have an intrinsic defect in myelin formation. ${ }^{25,26}$ Strikingly, the ISR is almost exclusively activated in astrocytes. ${ }^{7}$

\section{Therapy Targets and Compounds}

Considering the central role of the ISR in the pathophysiology of VWM, drugs targeting the ISR are of high therapeutic interest. A novel compound called ISRIB (abbreviation of ISR inhibitor) enhances eIF2B activity. ${ }^{27}$ ISRIB treatment of different VWM mice (2b5ho and 2b4ho2b5he) reduced expression of the ATF4 transcriptome, ameliorated white matter pathology, and improved motor skills, more so in the more severely affected $264 h o 2 b 5 h e$ than in $265 h$ mice. ${ }^{7}$ ISRIB stabilizes the eIF2B complex through interaction with the eIF2B $\delta$ :eIF2B $\beta$ interface and its effect may be influenced by individual gene variants. ${ }^{7} \mathrm{~A}$ derivative compound, 2BAct, has better pharmacologic properties and highly favorable results in $265 h o$ mice. ${ }^{9}$ At present, several eIF2B activators are in preclinical development.

Glycogen synthase kinase $3 \beta$ (GSK3 $\beta$ ) phosphorylates eIF2B $\varepsilon$, thereby reducing eIF2B activity. ${ }^{28}$ Antidepressant trazodone inhibits GSK3 $\beta$ and thereby ISR activation. ${ }^{29}$ Its 

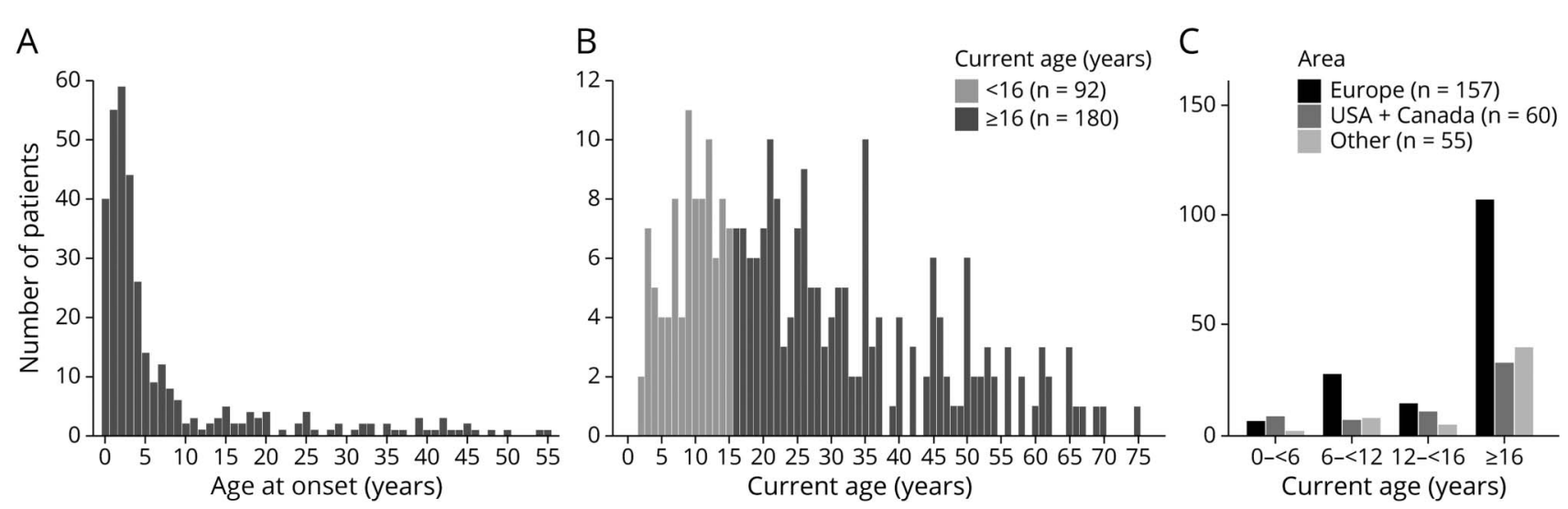

(A) Histogram representing the number of patients per age at onset (years) for 291 patients with VWM. Modified from Figure 1, Hamilton et al., Ann Neurol 2018, with permission. (B) Histogram representing the number of patients per current age (years) for 272 living patients with VWM known to the consortium (236 living patients in the international VWM registry and 36 living patients outside the registry followed by consortium members). (C) Histogram representing the number of patients per age group and region of residency for 272 living patients with VWM known to the consortium, showing that most living patients are $\geq 16$ years and diagnosed in Europe. $\mathrm{VWM}=$ vanishing white matter.

effects on VWM mice are being studied. Lithium also inhibits GSK3 $\beta$. In a zebrafish VWM model, ${ }^{30}$ lithium effects were promising, but safe doses in VWM mice appeared ineffective (unpublished data).

GADD34 is the entry of the feedback loop to reduce eIF2 phosphorylation. Guanabenz and sephin1 inhibit GADD34. ${ }^{31,32}$ Guanabenz is an old, Food and Drug Administration (FDA)-approved a2-adrenergic antihypertensive drug. Sephin1 has FDA orphan drug designation for Charcot-Marie-Tooth disease. As GADD34 inhibitors, they are expected to prolong ISR activation. Instead, for unknown reasons, both reduce ISR activation in mouse models of neurodegeneration. ${ }^{31,32}$ A recent trial shows some efficacy of guanabenz in patients with amyotrophic lateral sclerosis. ${ }^{33}$ Guanabenz had beneficial effects in VWM mice on neuropathology ${ }^{8}$ and motor performance (unpublished data). The effects of sephin1 on VWM mice are under study.

ATF4 and components of the ATF4 transcription response are a third target. It is clear that their overexpression is central in the pathophysiology of VWM. Reducing the expression of ATF4 or components of the ATF4 transcriptome by antisense oligonucleotides is of potential therapeutic interest, and a study on the subject is set up.

A fourth target are stressors provoking the ISR. Although it is difficult to prove the effect of preventive measures to avoid stressors, ${ }^{12}$ it is clear that occurrence of stress-provoked episodic decline is associated with poorer outcome. ${ }^{4}$ In addition, proteotoxic ER stress can potentially be reduced by compounds, like ursodiol and several other similar chaperone molecules. ${ }^{34}$ Assessment of their potential in VWM mice is ongoing.

Mitochondrial dysfunction may play a role in VWM disease mechanisms ${ }^{35}$ and could be favorably influenced by sigmal receptor agonists. ${ }^{35}$ Sigmal receptors function at the ERmitochondrial interface. Several sigmal receptor agonists are available, and studies of their effect in VWM mice are ongoing.

During rapid neurologic decline, steroids have been applied with unclear benefit. ${ }^{36}$ Steroids decrease levels of highmolecular-weight hyaluronan, which has been implicated in VWM pathomechanisms. ${ }^{24}$ A study in VWM mice failed to show beneficial effects (unpublished data).

Currently, eIF2B activators and guanabenz are most promising, showing improved motor performance and brain pathology in VWM mice. They are ready for clinical development. Similar results are not yet available for other compounds. Multiple ISR modulating compounds are undergoing preclinical development. Sigmal receptor agonists and steroids affect pathways further away from eIF2B, whereas ER chaperones only affect ER stress, leaving the other ISR activating stressors untouched. So far, only isolated effects of compounds are available; ongoing studies in VWM mice address the question whether a combination of drugs could prove more efficacious.

\section{Patient Numbers}

VWM is one of the more common leukodystrophies; US-based data from exome sequencing approaches indicate that VWM is fifth in relative incidence of leukodystrophies. ${ }^{37}$ Assessment of large genomic databases suggests an incidence of 1 per $715,000 .^{38}$ Centralized diagnostics in the Netherlands for 2 decades yield an incidence of 1 per 80,000-100,000 live births and prevalence of 1.4 per $1,000,000$ without evidence of founder effects. ${ }^{4}$ So, VWM is an ultra-rare disease, but clinical observations suggest a higher incidence than estimations based on databases.

Although disease incidence is highest at young ages, prevalence is mainly attributable to adolescent and adult patients. 
Although two-thirds of the patients in the natural history study have an onset $<6$ years (Figure $5 \mathrm{~A}$ ),${ }^{4}$ two-thirds of the known living patients are $\geq 16$ years (Figure $5 \mathrm{~B}$ ). Epidemiology varies greatly for different geographic areas (Figure 5C). No important consanguinity or founder effects were observed, suggesting that the higher incidence observed in Europe may reflect the actual incidence and that VWM may be underdiagnosed outside Europe, especially in adults (Figure 5C).

Enhanced awareness of VWM and improved access to genetic testing will increase diagnosis. Although MRI diagnosis is typically straightforward in pediatric patients, it is more difficult in adults, in whom cerebral white matter abnormalities are often nonspecific: more limited in extent, inhomogeneous, and characterized by atrophy rather than cystic decay, leading to misdiagnosis as atypical multiple sclerosis and vascular dementia. ${ }^{14}$ In the experience of consortium members, adult patients are mostly referred from multiple sclerosis or dementia centers.

\section{Biomarkers}

Only a few biomarkers have been identified for VWM, including elevated CSF glycine and decreased CSF asialotransferrin. . $^{39,40}$ Their sensitivity and proportionality have not been assessed. In view of emerging trials, there is an urgent need for biologically relevant biomarkers for VWM.

Biomarkers reflecting VWM pathomechanisms may be relevant to monitor target engagement of therapies. The ATF4 transcriptome provides excellent candidates, which can be assessed at RNA level in blood. In addition, VWM patients and mice display consistent evidence of metabolic derangement with altered amino acids, ${ }^{7,39}$ making metabolomics of interest. Biomarkers may also reflect tissue damage. Excellent candidates in this respect are neurofilament light (marker of axonal degeneration) and glial fibrillary acidic protein (marker of astrocytic degeneration). ${ }^{41}$

Identifying biomarkers in VWM mouse and patient samples and testing their longitudinal proportionality with disease severity are critical for implementing therapeutic trials. VWM mice can be tested for sensitivity to target engagement. Banked and ongoing VWM patient sample collections can be used to assess correlation of biomarkers with disease presence or absence, disease progression rate including acute exacerbations, and current disease severity, thereby revealing proportionality.

MRI also supplies possible biomarkers. Techniques providing quantitative parameters of white matter microstructure are particularly valuable and include diffusion tensor imaging (DTI), magnetization transfer ratio (MTR), myelin water fraction (MWF), multicomponent driven-equilibrium singlepulse observation of T1/T2 (mcDESPOT), neurite orientation dispersion and density imaging (NODDI), magnetic resonance spectroscopy (MRS), and quantitative susceptibility mapping. ${ }^{42}$ Volumetry with assessment of normal, abnormal but present, and rarefied or cystic white matter is another critical technique. ${ }^{14}$ MRI quantitative parameters are being assessed for their contribution in VWM.

\section{Clinical Trials in VWM}

\section{Expert Consensus}

The 9 consortium members had regular video meetings to discuss VWM pathophysiology, natural history, biomarkers, and clinical trial design. Recommendations were determined through rounds of voting. These votes are represented below by number of votes in favor ( $\mathrm{n}$ ) out of the 9 votes: consortium $\mathrm{n} / 9$. In addition, for recommendations regarding end points and scales for trials, a real-time Delphi, an expert-based consensus procedure, ${ }^{43}$ was executed among the 9 consortium members. Expert opinion on trial design and statistics was provided by the nonclinical advisors of the consortium and discussed within the consortium. Patient and family organizations on leukodystrophies were invited for comments.

\section{General Considerations and Recommendations}

In ultra-rare diseases, clinical trials are challenging. ${ }^{44}$ Very low patient numbers hamper meeting statistical standards for showing safety and efficacy of new drugs. ${ }^{45}$ Here, we discuss topics specifically pertinent to VWM.

The extremely heterogeneous clinical presentation and disease course challenge trial development in VWM. Age at onset is the best predictor of clinical course, ${ }^{4,11}$ and trials should either select specific age at onset groups or stratify for onset, thus creating more homogeneous subgroups (consortium 9/9). Despite a consistent genotype-phenotype correlation, the genotype does not add extra predictive information ${ }^{16}$ and does not require further stratification. In early-onset cases, motor decline is predominant; in late-onset cases, cognitive decline is predominant. ${ }^{4}$ We recommend separate trials for early and late onset (consortium 9/9). Although incidence of VWM is highest in infants and children, its prevalence is mostly attributable to adolescent and adult patients. Trials targeting patients with early onset will largely depend on newly diagnosed cases. Considering the variable and largely unpredictable disease course in VWM, ${ }^{4}$ followup needs to be sufficiently long for a trial to be informative.

Traditionally, the ideal setup for therapy trials, preferred by the FDA, Health Canada, and European Medicines Agency, is randomized, double blind, and placebo controlled, although particularly for ultra-rare disorders, novel trial designs have been adopted. ${ }^{46,47}$ In the adolescent and adult VWM population, progression is generally slow, and given the absence of other treatment options, double-blind placebo-controlled trials are preferable (consortium 9/9). With early onset, the disease course is more predictable and generally fast. In untreated patients with onset of $1-<2$ years, $\sim 65 \%$ lose ambulation, and $\sim 30 \%$ die within 4 years, whereas the numbers are $\sim 50 \%$ and $\sim 10 \%$, respectively, for patients with onset of $2-<4$ years. $^{6}$ These figures explain why parents of patients 
with early-onset VWM deem double-blind placebo-controlled trials unacceptable. The consortium (7/9) suggests that considering the predictable disease course of patients with early onset, ${ }^{4}$ existing natural history data may serve as control. Two consortium members would accept a placebo arm in trials for early-onset patients, on the condition that the double-blind study period would be less than 6 months, the treatment effect likely large, the number of patients receiving placebo small, and there would be an open-label extension.

\section{Inclusion and Exclusion Criteria}

The diagnosis of VWM needs to be genetically confirmed, and significant comorbidities, especially other genetic diseases, should be excluded (consortium 9/9). For trial participation, patients need to be clinically symptomatic (consortium 8/9). Presymptomatic patients, with genetically confirmed VWM but without neurologic signs, have unclear age at onset. Even for familial cases, considerable intrafamilial variation hampers prediction of onset. ${ }^{4}$ When suitable biomarkers have been developed that are proportionate to disease evolution, either biochemical or MRI parameter, inclusion of clinically presymptomatic patients can be considered.

Stage of disease progression is an important consideration in choosing pivotal trial populations. Multiple studies in other leukodystrophies have shown that therapies are effective only early in the disease. ${ }^{48}$ As long as the general white matter structure is largely preserved, damage may be reparable, but cystic white matter cannot be repaired. Halting further clinical disease progression under therapy is measurable early in the disease, but in far advanced stages, arrest of further progression may not be discernible. For these reasons, trials should focus on patients early in the disease (consortium 8/9, see text below for specifics). One consortium member voted for inclusion of patients with more advanced disease.

Strict criteria are acceptable to enhance the chance of a definitive trial outcome (consortium 8/9), but leave numerous patients with VWM noneligible for efficacy trials. Compassionate use and expanded access programs should be considered for such patients and their data should be analyzed separately and used for additional refinement of treatment criteria (consortium 9/9).

\section{Recommendations per Age at Onset}

Patients with onset $<1$ year have a severe encephalopathy, often multiorgan involvement, and early death. ${ }^{4}$ Even with prenatal diagnosis, the brain is already severely affected at birth. Damage is thus likely irreparable at trial entry and hampers detection of treatment effects. The consortium (7/ 9) would advise to not include them in upcoming efficacy trials, but consider compassionate use or expanded access programs.

Patients with late infantile and early childhood onset have a rapid and rather predictable course. ${ }^{4}$ Relatively small and short trials may suffice to show efficacy of an intervention (consortium 9/9; see below for statistical calculations). Results of the natural history study indicate that for early onset, ambulation and survival are sensitive parameters to assess efficacy (Figure 1). ${ }^{4}$ In analogy with trial design in late infantile metachromatic leukodystrophy (MLD), ${ }^{49}$ ambulation without or with minimal support of one hand (10-step-walk test, item of the GMFM-88) is suitable as inclusion criterion (consortium 9/9).

For patients with onset after early childhood, disease course and life span are unpredictable. ${ }^{4}$ Therefore, double-blind placebo-controlled trials are highly preferable (consortium 9/9). Childhood presentation is predominantly motor, and adult presentation is predominantly behavioral and cognitive, whereas the presentation is variable or mixed for ages in between. Inclusion criteria and outcome parameters should reflect those issues. Patients should be included early, while ambulant and having relatively preserved cognitive functions (consortium 9/9).

\section{Recommendation on Scales and End Points}

Clinical end points must be meaningful, assessable in a standardized manner, preferably with established instruments, and should ideally be validated or at least previously used in VWM. The instruments should cover different functional domains, in particular motor, cognitive, emotional, and behavioral domains and should ideally be usable for different ages. Currently, no single instrument meets all criteria.

Optimal inclusion of the limited number of patients with VWM eligible for trials requires sharing of data, which necessitates open access to control data across trials and standardized core end points, which allow pooling of data from control arms and compare efficacy of therapies tested in different trials. Therefore, the 9 consortium members defined a core set of instruments for trials in VWM. To reach consensus, a modified real-time (rt) Delphi procedure was executed, using EDELPHI 2021 software. $^{43}$ This online software tool allows participants to give and revise their opinion within a predefined period. A systematic literature review on VWM and a recently performed Delphi procedure among experts on MLD served as input; consortium members could add scales and questionnaires, based on individual experience. In total, 24 clinical scales and questionnaires were reviewed. The 16 recommended instruments that comprehensively assess all relevant clinical domains are presented in Table 2 and supplementary file, links.lww.com/NXG/A512.

Currently, body fluid biomarkers, discussed above, and quantitative MRI parameters relevant to brain white matter integrity provide exploratory outcome measures. The standard MRI protocol to assess white matter integrity should comprise a highresolution T1-weighted sequence (magnetization-prepared rapid gradient echo sequence) and T2-weighted and FLAIR sequences. All sequences should cover the entire intracranial cavity for segmentation and volumetry. To investigate white matter microstructure, a multimodal MRI protocol at higher 
Table 2 Outcome Measures

\begin{tabular}{|c|c|c|c|c|c|c|}
\hline & $\begin{array}{l}\text { Validated for } \\
\text { age range }(y)\end{array}$ & $\begin{array}{l}\text { Specifically validated for } \\
\text { leukodystrophies }\end{array}$ & $\begin{array}{l}\text { Previously applied in } \\
\text { leukodystrophies }\end{array}$ & Applied in VWM & Reported by & $\begin{array}{l}\text { Clinically } \\
\text { meaningful }\end{array}$ \\
\hline \multicolumn{7}{|c|}{$\begin{array}{l}\text { QoL and level of } \\
\text { functioning }\end{array}$} \\
\hline HUI3 & 1 scale, $\geq 1$ & No & Yes & Yes & P\&P or clinician & Yes \\
\hline PedsQL & 4 scales, 2-18 & No & Yes & Yes (unpublished) & $P \& P$ & Yes \\
\hline EQ5D5L & 3 scales, $\geq 4$ & No & No & Yes (unpublished) & $P \& P$ & Yes \\
\hline \multicolumn{7}{|l|}{ Motor scales } \\
\hline GMFM-88 & 1 scale, $\geq 1 / 2$ & No & Yes & Yes (unpublished) & Trained expert & Limited \\
\hline $\begin{array}{r}\text { 10MWT/ } \\
\text { 10SWT }\end{array}$ & $\geq 2$ & No & Yes & Yes (unpublished) & Clinician & Yes \\
\hline GMFC-MLD & 1 scale, $\geq 1 \frac{1}{2}$ & Yes & Yes & Yes (unpublished) & Clinician & Yes \\
\hline GMFCS & 1 scale, $\geq 1 \frac{1}{2}$ & No & Yes & Yes (unpublished) & Clinician & Yes \\
\hline (Mini-)MACS & 2 scales, $\geq 1$ & No & Yes (unpublished) & Yes (unpublished) & Clinician & Yes \\
\hline SARA & 1 scale, $\geq 8$ & No & Yes (unpublished) & No & Clinician & Limited \\
\hline BARS & 1 scale, $\geq 4$ & No & No & No & Clinician & Limited \\
\hline \multicolumn{7}{|l|}{$\begin{array}{l}\text { Eating and } \\
\text { drinking }\end{array}$} \\
\hline EDACS & 1 scale, $\geq 2$ & & Yes (unpublished) & Yes (unpublished) & Clinician & Yes \\
\hline \multicolumn{7}{|c|}{ Communication } \\
\hline CFCS & 1 scale, $\geq 2$ & No & No & Yes (unpublished) & Clinician & Yes \\
\hline ELFC-MLD & 1 scale, $\geq 1 \frac{1}{2}$ & Yes & Yes & Yes (unpublished) & Clinician & Yes \\
\hline \multicolumn{7}{|c|}{ Cognitive scales } \\
\hline LIPS & $\geq 2$ & No & No & Yes (unpublished) & Trained expert & Limited \\
\hline $\begin{array}{l}\text { Wechsler } \\
\text { scales }\end{array}$ & $\geq 2^{a}$ & No & Yes & No & Trained expert & Limited \\
\hline \multicolumn{7}{|l|}{$\begin{array}{l}\text { Adaptive } \\
\text { behavior scales }\end{array}$} \\
\hline Vineland-3 & $0-90$ & No & No & No & $\begin{array}{l}\text { Parent, teacher, or } \\
\text { partner }\end{array}$ & Yes \\
\hline $\begin{array}{l}\text { Abbreviations: } 1 \\
\text { System; CFCS = } \\
\text { GMFC-MLD = Gr } \\
\text { Health Utilities I } \\
\text { PedsQL = Pediat } \\
\text { References for a } \\
\text { a Different tests }\end{array}$ & $\begin{array}{l}\text { WT }=10 \mathrm{~m} \text { wal } \\
\text { imunication Fu } \\
\text { Motor Functior } \\
\text { ex Mark 3; LIPS } \\
\text { Quality of Life I } \\
\text { cales are preser } \\
\text { different age ra }\end{array}$ & $\begin{array}{l}\text { est; } 10 \text { SWT = 10-step-walk t } \\
\text { tion Classification System; EL } \\
\text { lassification for MLD; GMFC } \\
\text { Leiter International Perform } \\
\text { entory; QoL = quality of life; } \\
\text { d in the supplementary file, } \\
\text { ges; a selection of subtests }\end{array}$ & $\begin{array}{l}\text { st; BARS = Brief Ataxia R } \\
\text { FC-MLD = Expressive Lan } \\
=\text { General Motor Classif } \\
\text { ance Scale; MACS = Man } \\
\text { SARA = Scale for Assessm } \\
\text { links.Iww.com/NXG/A512 } \\
\text { an be used focused on co }\end{array}$ & $\begin{array}{l}\text { ting Scale = EDACS } \\
\text { dage Function Classif } \\
\text { ation System; GMFN } \\
\text { al Ability Classificatio } \\
\text { nt and Rating of Ata } \\
\text { nitive impairment in }\end{array}$ & $\begin{array}{l}\text { g and Drinking Abilit } \\
\text { for MLD; EQ5D5L = } \\
\text { Ss Motor Function M } \\
\text { em; P\&P = patients a } \\
\text { RA); VWM = vanishing } \\
\text { dystrophies. }\end{array}$ & $\begin{array}{l}\text { Classification } \\
\text { uroQol 5D/5L; } \\
\text { easure; HUI3 = } \\
\text { nd/or proxies; } \\
\text { white matter. }\end{array}$ \\
\hline
\end{tabular}

field strength $(3 \mathrm{~T})$ is recommended, including sequences as DTI, MTR, NODDI, MWF, mcDESPOT, MRS, and quantitative susceptibility mapping. ${ }^{42}$

\section{Trial Safety Considerations}

Given that the ISR is a protective response, an important question is whether eIF2B activity can still be adequately modulated in the context of stress. A reassuring finding is that cells are insensitive to ISRIB during acute ISR activation and that cytoprotective ISR effects remain intact. ${ }^{50}$ Another concern may be that enhanced eIF2B activity stimulates growth and may be associated with an increased long-term risk of cancer. ${ }^{51,52}$

\section{Innovative Trial Design}

Given that VWM is ultra-rare and that potentially different drugs will need to be assessed in trials that overlap in time, trial strategies should be extremely well planned and maximize the contribution of the few eligible patients. We propose the use of (1) statistical methods that incorporate historical data in the assessment of efficacy and (2) platform trials or other trial designs using a common, shared core protocol. 
In settings of general consensus that placebo-controlled trials are considered unethical, for instance because of high death rates without therapy and highly promising preclinical studies, singlearm trials should be considered. Data from natural history studies may serve as an indirect comparator for such single-arm trials by providing an external control group that received standard of care. Furthermore, historical data may augment control arm data in 2-arm trials, thereby allowing a lower number of patients randomized to the control arm. The latter is generally referred to as historical borrowing. ${ }^{53}$ Historical control information may allow single-arm studies in patients with VWM with late infantile and early childhood onset. As soon as the first efficacious drug has been identified, subsequent trials can use this drug as active control arm. Data from the single-arm trial for the first efficacious drug could potentially be used as historical control data to enrich subsequent trials and increase power.

Platform trials use a single master protocol to simultaneously evaluate multiple experimental treatments. ${ }^{54,55}$ The master protocol defines the inclusion and exclusion criteria. On inclusion, a patient is randomized to the control arm or one of the experimental treatment arms. As the control arm can be used as a comparator for multiple experimental treatments, the number of participants that needs to be allocated to control treatment is substantially reduced compared with a standard setting, in which separate placebo-controlled trials are run for each experimental drug. Platform trials can be adaptive in nature, allowing treatments to be declared futile or efficacious at interim analyses. Platform trials using a single master protocol also provide a durable infrastructure for treatment evaluation, in which new experimental treatments can be evaluated as soon as they become available.

If separate trials are run for different dugs, sharing data of patients in control arms allows a larger proportion of patients to be randomized to experimental therapies. A limited core protocol can be designed, in which only the inclusion and exclusion criteria, a limited set of outcome measures and assessment intervals, are determined to allow sharing of control data. Outside the core protocol, each trial can decide on numbers and trial duration, prioritize and add outcome measures, and plan studies on biomarkers and pharmacokinetics. Different core protocols can be designed for patients with early- and late-onset VWM.

\section{Sample Size and Statistics}

In single-arm trials with historical control data, adequate matching or use of analyses adjusting for confounding variables is essential. Historical controls and trial participants should be matched for age at onset. Matching for genotype is not advisable because of the very high number of different pathogenic variants and because the genotype does not add predictive information in addition to age at onset. Depending on the number of patients in the natural history cohort satisfying the trial inclusion criteria, different methods can be considered to reduce bias in estimates of treatment effects. Appropriate methods include one-to-many matching, propensity score matching, or adjustment for age at onset and other possible confounders in a regression framework. Statistical methods should take into consideration the nature of the matching, with weighted least squares analysis typically required when one-to-many matching is used.

Single-arm trials can be adequately powered for detection of large treatment effects. The current single-arm trial investigating the efficacy of guanabenz in ambulatory patients with VWM with age at onset $<6$ years (clinicaltrialsregister.eu/ ctr-search/trial/2017-001438-25/NL) uses time until loss of ambulation as the primary efficacy outcome measure. To estimate the number of patients needed, we determined that in the absence of treatment, based on the VWM natural history study, ${ }^{4}$ the proportion of ambulatory patients 2 years after disease onset is estimated to be approximately $60 \%$. For a power of $80 \%$ and a 2 -sided significance of less than $5 \%$, a single-arm trial with 34 patients and an equal number of historical controls allows detection of an absolute increase of $25 \%$ of ambulatory patients. This calculation assumed that both the accrual time and the minimum follow-up time are 2 years.

In the adolescent and adult VWM population, randomized controlled trials can likely be adequately powered for detection of large treatment effects. Based on data from the VWM natural history study, ${ }^{4}$ the average decline in HUI cognition score in patients with an onset $\geq 16$ years in the 2 years after onset was estimated to be 0.12 points with an SD of 0.15 . Under the assumption that the experimental treatment stops the cognitive decline, a sample size of 26 patients per arm would suffice to demonstrate a difference in mean 2-year cognitive decline relative to placebo, with $80 \%$ power assuming 2 -sided testing at a $5 \%$ significance level. Use of repeatedly measured outcomes could increase power and allows detection of smaller effects.

\section{Conclusions and Recommendations}

VWM is a fatal disease with serious morbidities. Apart from measures to prevent stressors provoking acute deteriorations, only symptomatic care is available. This grim situation is shifting. Different molecular targets have been identified, and several drugs are in clinical development. Efficacy trials are, however, challenged by the low number of known patients with VWM, clinical variability, and unpredictable disease course for onsets after early childhood. Given these challenges and the critical need to offer therapies, we have formulated recommendations based on evaluation of available clinical, laboratory, and molecular data:

1. Increase the diagnostic rate of VWM. Undiagnosed patients have no access to promising new drugs and cannot contribute to their evaluation in trials.

2. Develop biomarkers that can be used in therapy trials. Both body fluid and MRI biomarkers are promising. Their responsiveness to intervention and proportionality should be explored in initial trials to provide evidentiary criteria for future interventional trials.

3. For patients with late infantile and early childhood disease, a single-arm open-label study is recommended until an effective 
therapy is determined. In this group, disease course is predictable, and matching with historical controls is possible. After demonstrating the efficacy of the first drug, subsequent studies can be double blind and controlled, with the use of platform design or core protocols to maximize the number of patients treated with new drugs. Pivotal populations should consider disease stage; preserved ambulation or other motor function could serve as inclusion criterion. Stabilization or improvement of motor skills can serve as primary outcome measure.

4. For patients with onset after early childhood, disease course and life span are variable and unpredictable. Therefore, double-blind placebo-controlled trials are preferable and must be of sufficient duration. Inclusion criteria and outcome measures should reflect the variable age-dependent presentations. Patients should be included early in the disease, while ambulant and having relatively preserved cognitive function. Use of platform design or core protocols with shared controls for different drugs helps minimize the number of patients on placebo and maximize the patients on trial drugs, facilitating unbiased comparison of different drugs.

5. Data from all trials should be shared. Therefore, all trials should use a minimum common set of outcome measures (Table 2).

6. Compassionate use and expanded access programs for trial drugs should be considered for patients not fulfilling the inclusion criteria.

The opportunity to advance therapy for VWM will depend on collaboration of patients and families, clinicians, industries, and regulatory agencies, with the aim to coordinate and successfully execute trials, to ensure rapid drug assessments, and to deliver treatments to patients.

\section{Acknowledgment}

The authors thank Prof. Arjen B. Brussaard, director of Amsterdam Neuroscience, The Netherlands, for his continuous support of the VWM consortium. The authors are grateful to Daphne Schoenmakers, $\mathrm{MD}$ and $\mathrm{PhD}$ student at the Department of Child Neurology, Amsterdam University Medical Center, The Netherlands, for setting up and executing the Delphi procedure. The authors thank Menno Stellingwerff, MD and $\mathrm{PhD}$ student at the Department of Child Neurology, Amsterdam University Medical Center, for providing numbers and figures from the VWM registry. MSvdK, EB, IK-M, and NIW are members of the European Reference Network for Rare Neurological Disorders (ERN-RND), project ID 739510. AV, $\mathrm{JLB}$, and AF are members of the Global Leukodystrophy Initiative Clinical Trials Network (GLIA-CTN), U54NS115052.

\section{Study Funding}

No targeted funding reported.

\section{Disclosure}

M.S. van der Knaap is a consultant for Calico and coinvestigator for the Alexander disease trial of Ionis and received research support from the NWO Spinoza award, ZonMw TOP grant 91217006, European Leukodystrophy Foundation grant 2017-02712,
European Leukodystrophy Foundation grant 2019-P001, Hersenstichting grant DR-2019-00285, Vanishing White Matter Foundation, Chloe Saxby and VWM Disease Incorporated, and VWM Families Foundation Inc. She has a patent P112686CA00, therapeutic effects of Guanabenz treatment in vanishing white matter, pending to VU University Medical Center. She is principal investigator of the Guanabenz trial (EU Clinical Trials register with EudraCT number 2017-001438-25, clinicaltrialsregister.eu/ctrsearch/trial/2017-001438-25/NL; and Dutch Trial Register with trial number NL7260, trialregister.nl/trial/7260). She is editorial board member of Neuropediatrics. J.L. Bonkowsky is consultant for Autobahn Therapeutics, Bluebird Bio, Calico, Enzyvant, Denali Therapeutics, Neurogene, and Passage Bio; is serving on the Board of Directors of wFluidx; holds stock options in Orchard Therapeutics; receives royalties from Manson Publishing, and his spouse receives royalties from BioMerieux; and receives research support from the NIH NINDS (5U54NS115052), NCATS as part of the Rare Disease Consortia Research Network, and Vanishing White Matter Foundation. A. Vanderver receives research support from Eli Lilly, Biogen, Ionis, Illumina, Takeda, PMD Foundation, UK H-ABC Foundation, and Calliope Joy Foundation. She is on scientific advisory boards of the United Leukodystrophy Foundation, European Leukodystrophy Association, Yaya Foundation, Biogen, Homology, Ionis, Homology, Passage Bio, and Orchard Therapeutics in an unpaid capacity. She receives research support from NICHD, NINDS for research in Aicardi Goutières Syndrome and receives research support from the NIH NINDS/NCATS (5U54NS115052) as part of the Rare Disease Consortia Research Network. She has a patent on therapeutics in TUBB4A associated leukodystrophy. She has a license on a disease severity scale in Aicardi Goutières Syndrome R. Schiffmann is a consultant for Calico. I. Krägeloh-Mann is a member of the scientific advisory board of Orchard and receives travel grants from Shire. E. Bertini is a coinvestigator for the Alexander disease trial of Ionis; is a scientific committee member of the European Leukodystrophy Association; and receives research support from Ricerca Corrente Ministero della Salute, Italy. G. Bernard is a consultant for Passage Bio Inc (2020-2021) and Ionis (2019). She is a site investigator for the Alexander disease trial of Ionis (2021), Metachromatic leukodystrophy of Shire/Takeda (2020-2021), Krabbe and GM1 gene therapy trials of Passage Bio (2021), and Adrenoleukodystrophy/ Hematopoietic stem cell transplantation natural history study of Bluebird Bio (2019) and a site subinvestigator for the MPS II gene therapy trial of Regenxbio (2021). She has received an unrestricted educational grant from Takeda (2021). She receives research support from the Canadian Institutes for Health Research (project grant 426534 and 201610PJT-377869), Montreal Children's Foundation, Fondation Les Amis d'Elliot, Pelizaeus-Merzbacher Disease Foundation, Foundation of Stars, Healthy Brains Healthy Lives, Fondation le Tout pour Loo, Leuco-Action, Rare Diseases Foundation and BC Children's Foundation, Canada Summer Jobs, McGill University Health Center Department of Medicine CAS Clinical Research Funding, Healthy Brains and Healthy Lives, and The Yaya Foundation for 4H Leukodystrophy. She has received a Clinical Research Scholar Junior 1 award from the Fonds de Recherche du Quebec-Santé (FRQS) (2012-2016), the New Investigator Salary Award from the Canadian Institutes of Health 
Research (2017-2022), and the Clinical Research Scholar Senior award from the FRQS (2022-2025). She serves on the scientific advisory board of the Pelizaeus-Merzbacher Foundation and is the Chair of the Medical Advisory Board of the United Leukodystrophy Foundation. She is on the editorial boards of Neurology Genetics, Frontiers in Neurology-Neurogenetics, and Journal of Medical Genetics. A. Fatemi is a member of the data safety monitoring boards of Bluebird Bio, Everest Clinical Research, and Nuvelution; is a scientific advisory board member of Orpheris and Autobahn therapeutics; and is a consultant for Calico Labs, Vertex Pharmaceuticals, BlueRock Therapeutics, Autobahn therapeutics, Orpheris, Poxel, and SwanBio Therapeutics. He is Board of Directors member of ALD Connect and scientific advisory board member of A Cure for Ellie and Vice Chair of the United Leukodystrophy Foundation. He is involved in clinical trials from Minoryx; receives research support from Neurovia, Viking Therapeutics, NICHD (grant P50HD103538, Intellectual and Developmental Disabilities Research Centers) and NINDS and NCATS (grant U54NS115052, Rare Disease Consortia Research Network). N. I. Wolf is consultant for Passage Bio, Ionis, and Orchard and coinvestigator for the Metachromatic leukodystrophy trial of Shire/Takeda. She receives research support from Metakids and ZonMW. She is in the scientific advisory board of the European Leukodystrophy Association (ELA), Mission Massimo, and Yaya Foundation. She is editor of Neuropediatrics and member of the editorial boards of Neurology and European Journal of Pediatric Neurology. E.F. Saunier-Vivar, R Rauner, H. Dekker, P. van Bokhoven, P.M. van de Ven, and P.S. Leferink report no disclosures. Go to Neurology.org/NG for full disclosures.

\section{Publication History}

Received by Neurology: Genetics September 20, 2021. Accepted in final form December 21, 2021. Submitted and externally peer reviewed. The handling editor was Stefan M. Pulst, MD, Dr med, FAAN.

\section{Appendix Authors}

\begin{tabular}{|c|c|c|}
\hline Name & Location & Contribution \\
\hline $\begin{array}{l}\text { Marjo S. van } \\
\text { der Knaap, } \\
\text { MD, PhD }\end{array}$ & $\begin{array}{l}\text { Department of Pediatric } \\
\text { Neurology, Amsterdam } \\
\text { Leukodystrophy Center, } \\
\text { Emma Children's Hospital, } \\
\text { Amsterdam University } \\
\text { Medical Centers; Amsterdam } \\
\text { Neuroscience; Department } \\
\text { of Functional Genomics, } \\
\text { Center for Neurogenomics } \\
\text { and Cognitive Research, Vrije } \\
\text { Universiteit, Amsterdam, the } \\
\text { Netherlands }\end{array}$ & $\begin{array}{l}\text { Drafting/revision of the } \\
\text { manuscript for content, } \\
\text { including medical writing } \\
\text { for content; major role in } \\
\text { the acquisition of data; } \\
\text { study concept or design; } \\
\text { and analysis or } \\
\text { interpretation of data }\end{array}$ \\
\hline $\begin{array}{l}\text { Joshua L. } \\
\text { Bonkowsky, } \\
\text { MD }\end{array}$ & $\begin{array}{l}\text { Division of Pediatric } \\
\text { Neurology, Department of } \\
\text { Pediatrics, University of Utah } \\
\text { School of Medicine; Primary } \\
\text { Children's Hospital, } \\
\text { Intermountain Healthcare, } \\
\text { Salt Lake City, UT }\end{array}$ & $\begin{array}{l}\text { Drafting/revision of the } \\
\text { manuscript for content, } \\
\text { including medical writing } \\
\text { for content; major role in } \\
\text { the acquisition of data; } \\
\text { study concept or design; } \\
\text { and analysis or } \\
\text { interpretation of data }\end{array}$ \\
\hline
\end{tabular}

Appendix (continued)

\begin{tabular}{|c|c|c|}
\hline Name & Location & Contribution \\
\hline $\begin{array}{l}\text { Adeline } \\
\text { Vanderver, } \\
\text { MD }\end{array}$ & $\begin{array}{l}\text { Division of Neurology, } \\
\text { Children's Hospital of } \\
\text { Philadelphia; Department of } \\
\text { Neurology, Perelman School } \\
\text { of Medicine, University of } \\
\text { Pennsylvania, PA }\end{array}$ & $\begin{array}{l}\text { Drafting/revision of the } \\
\text { manuscript for content, } \\
\text { including medical writing } \\
\text { for content; major role in } \\
\text { the acquisition of data; } \\
\text { study concept or design; } \\
\text { and analysis or } \\
\text { interpretation of data }\end{array}$ \\
\hline
\end{tabular}

Raphael 4D Molecular Therapeutics, Drafting/revision of the

Schiffmann, Emeryville, CA manuscript for content,

MD including medical writing for content; major role in the acquisition of data; study concept or design; and analysis or interpretation of data

\begin{tabular}{ll}
\hline Ingeborg & Department of \\
Krägeloh- & Developmental and Child \\
Mann, MD, & Neurology, Social Pediatrics, \\
PhD & University Children's \\
& Hospital Tübingen, Germany
\end{tabular}

Drafting/revision of the manuscript for content, including medical writing for content; major role in the acquisition of data; study concept or design; and analysis or interpretation of data

\begin{tabular}{lll}
\hline Enrico & Department of & Drafting/revision of the \\
Bertini, MD, & Neuroscience, Unit of & manuscript for content, \\
PhD & Neuromuscular and & including medical writing \\
& Neurodegenerative & for content; major role in \\
& Diseases, Laboratory of & the acquisition of data; \\
& Molecular Medicine, & study concept or design; \\
& Genetics and Rare Diseases & and analysis or \\
& Research Division, IRCCS & interpretation of data \\
& Ospedale Pediatrico & \\
Bambino Gesù, Rome, Italy &
\end{tabular}

Genevieve Departments of Neurology Drafting/revision of the Bernard, MD, and Neurosurgery, Pediatrics manuscript for content, MSc and Human Genetics, McGill University; Department for content; major role in Specialized Medicine, Division the acquisition of data; of Medical Genetics, McGill study concept or design; University Health Center; and analysis or Child Health and Human interpretation of data Development Program, Research Institute of the McGill University Health Center, Montreal, Canada

\begin{tabular}{ll}
\hline Seyed Ali & Kennedy Krieger Institute, \\
Fatemi, MD & Johns Hopkins University,
\end{tabular}
Baltimore, MD

Drafting/revision of the manuscript for content, including medical writing for content; major role in the acquisition of data; study concept or design; and analysis or interpretation of data

\begin{tabular}{lll}
\hline $\begin{array}{l}\text { Nicole I. } \\
\text { Wolf, MD, } \\
\text { PhD }\end{array}$ & $\begin{array}{l}\text { Department of Pediatric } \\
\text { Neurology, Amsterdam } \\
\text { Leukodystrophy Center, } \\
\text { Emma Children's Hospital, } \\
\text { Amsterdam University } \\
\text { Medical Centers; Amsterdam } \\
\text { Neuroscience }\end{array}$ & $\begin{array}{l}\text { Drafting/revision of the } \\
\text { manuscript for content, } \\
\text { including medical writing for } \\
\text { content; major role in the } \\
\text { acquisition of data; study } \\
\text { concept or design; and analysis } \\
\text { or interpretation of data }\end{array}$ \\
\hline $\begin{array}{ll}\text { Elise Saunier- } \\
\text { Vivar, PhD }\end{array}$ & $\begin{array}{l}\text { Research Department, } \\
\text { European Leukodystrophies } \\
\text { Association International } \\
\text { and European } \\
\text { Leukodystrophies } \\
\text { Association France, Paris, } \\
\text { France }\end{array}$ & $\begin{array}{l}\text { Drafting/revision of the } \\
\text { manuscript for content, } \\
\text { including medical writing } \\
\text { for content; major role in } \\
\text { the acquisition of data; } \\
\text { study concept or design; } \\
\text { and analysis or } \\
\text { interpretation of data }\end{array}$ \\
& &
\end{tabular}


Appendix (continued)

\begin{tabular}{lll}
\hline Name & Location & Contribution \\
\hline $\begin{array}{l}\text { Robert } \\
\text { Rauner }\end{array}$ & United Leukodystrophy & $\begin{array}{l}\text { Drafting/revision of the } \\
\text { manuscript for content, } \\
\text { including medical writing } \\
\text { for content; major role in } \\
\text { the acquisition of data; } \\
\text { study concept or design; } \\
\end{array}$ \\
& $\begin{array}{l}\text { and analysis or } \\
\text { interpretation of data }\end{array}$
\end{tabular}

\begin{tabular}{ll}
\hline Hanka & Vereniging Volwassenen, \\
Dekker & Kinderen en \\
& Stofwisselingsziekten,
\end{tabular}

Zwolle, the Netherlands

Drafting/revision of the manuscript for content, including medical writing for content; major role in the acquisition of data; study concept or design; and analysis or interpretation of data

\begin{tabular}{lll}
\hline Pieter van & Industry Alliance Office, & Drafting/revision of the \\
Bokhoven, & Amsterdam Neuroscience, & manuscript for content, \\
PhD & Amsterdam University & including medical writing \\
Medical Centers, the & for content; major role in \\
Netherlands & the acquisition of data; \\
& & study concept or design; \\
and analysis or \\
interpretation of data
\end{tabular}

\begin{tabular}{|c|c|c|}
\hline $\begin{array}{l}\text { Peter van de } \\
\text { Ven, PhD }\end{array}$ & $\begin{array}{l}\text { Department of Epidemiology } \\
\text { and Data Science, } \\
\text { Amsterdam University } \\
\text { Medical Centers, Vrije } \\
\text { Universiteit, Amsterdam, the } \\
\text { Netherlands }\end{array}$ & $\begin{array}{l}\text { Drafting/revision of the } \\
\text { manuscript for content, } \\
\text { including medical writing } \\
\text { for content; major role in } \\
\text { the acquisition of data; } \\
\text { study concept or design; } \\
\text { and analysis or } \\
\text { interpretation of data }\end{array}$ \\
\hline $\begin{array}{l}\text { Prisca S. } \\
\text { Leferink, } \\
\text { PhD }\end{array}$ & $\begin{array}{l}\text { Industry Alliance Office, } \\
\text { Amsterdam Neuroscience, } \\
\text { Amsterdam University } \\
\text { Medical Centers, the } \\
\text { Netherlands }\end{array}$ & $\begin{array}{l}\text { Drafting/revision of the } \\
\text { manuscript for content, } \\
\text { including medical writing } \\
\text { for content; major role in } \\
\text { the acquisition of data; } \\
\text { study concept or design; } \\
\text { and analysis or } \\
\text { interpretation of data }\end{array}$ \\
\hline
\end{tabular}

\section{References}

1. Hanefeld F, Holzbach U, Kruse B, Wilichowski E, Christen HJ, Frahm J. Diffuse white matter disease in three children: an encephalopathy with unique features on magnetic resonance imaging and proton magnetic resonance spectroscopy. Neuropediatrics. 1993;24(5):244-248.

2. Schiffmann R, Moller JR, Trapp BD, et al. Childhood ataxia with diffuse central nervous system hypomyelination. Ann Neurol. 1994;35(3):331-340.

3. van der Knaap MS, Barth PG, Gabreëls FJ, et al. A new leukoencephalopathy with vanishing white matter. Neurology. 1997;48(4):845-855.

4. Hamilton EMC, van der Lei HDW, Vermeulen G, et al. Natural history of vanishing white matter. Ann Neurol. 2018;84(2):274-288.

5. Leegwater PA, Vermeulen G, Könst AA, et al. Subunits of the translation initiation factor eIF2B are mutant in leukoencephalopathy with vanishing white matter. Nat Genet. 2001;29(4):383-388.

6. Scheper GC, van der Knaap MS, Proud CG. Translation matters: protein synthesis defects in inherited disease. Nat Rev Genet. 2007;8:711-723.

7. Abbink TEM, Wisse LE, Jaku E, et al. Vanishing white matter: deregulated integrated stress response as therapy target. Ann Clin Transl Neurol. 2019;6(8): 1407-1422.

8. Dooves S, Bugiani M, Wisse LE, Abbink TEM, van der Knaap MS, Heine VM. Bergmann glia translocation: a new disease marker for vanishing white matter identifies therapeutic effects of Guanabenz treatment. Neuropathol Appl Neurobiol. 2018; 44(4):391-403.

9. Wong YL, LeBon L, Basso AM, et al. eIF2B activator prevents neurological defects caused by a chronic integrated stress response. Elife. 2019;8:e42940.

10. Vanishing White Matter Consortium. vwmconsortium.org.

11. Fogli A, Schiffmann R, Bertini E, et al. The effect of genotype on the natural history of eIF2B-related leukodystrophies. Neurology. 2004;62(9):1509-1517.

12. van der Knaap MS, Pronk JC, Scheper GC. Vanishing white matter disease. Lancet Neurol. 2006;5:413-423.
13. van der Lei HD, Steenweg ME, Barkhof F, et al. Characteristics of early MRI in children and adolescents with vanishing white matter. Neuropediatrics. 2012;43(1): 22-26.

14. Stellingwerff MD, Al-Saady ML, van de Brug T, et al. MRI natural history of the leukodystrophy vanishing white matter. Radiology. 2021;300(3):671-680.

15. van der Lei HD, van Berkel CG, van Wieringen WN, et al. Genotype-phenotype correlation in vanishing white matter disease. Neurology. 2010;75(17): 1555-1559.

16. Slynko I, Nguyen S, Hamilton EMC, et al. Vanishing white matter: eukaryotic initiation factor 2B model and the impact of missense mutations. Mol Genet Genomic Med. 2021;9(3):e1593.

17. Dever TE. Gene-specific regulation by general translation factors. Cell. 2002;108(4): 545-556.

18. Pavitt GD. eIF2B, a mediator of general and gene-specific translational control. Biochem Soc Trans. 2005;33(pt 6):1487-1492.

19. Proud CG. eIF2 and the control of cell physiology. Semin Cell Dev Biol. 2005;16(1): 3-12.

20. Pakos-Zebrucka K, Koryga I, Mnich K, et al. The integrated stress response. EMBO Rep. 2016;17(10):1374-1395.

21. Li W, Wang X, van der Knaap MS, Proud CG. Mutations linked to leukoencephalopathy with vanishing white matter impair the function of the eukaryotic initiation factor 2B complex in diverse ways. Mol Cell Biol. 2004;24(8):3295-3306.

22. Van Haren K, van der Voorn JP, van der Knaap MS, Powers JM. The life and death of oligodendrocytes in vanishing white matter disease. J Neuropathol Exp Neurol. 2004; 63(6):618-630.

23. Bugiani M, Vuong C, Breur M, van der Knaap MS. Vanishing white matter: a leukodystrophy due to astrocytic dysfunction. Brain Pathol. 2018;28(3):408-421.

24. Bugiani M, Postma N, Polder E, et al. Hyaluronan accumulation and arrested oligodendrocyte progenitor maturation in vanishing white matter disease. Brain. 2013; 136(pt 1):209-222.

25. Dooves S, Bugiani M, Postma NL, et al. Astrocytes are central in the pathomechanisms of vanishing white matter. J Clin Invest. 2016;126(4):1512-1524.

26. Leferink PS, Dooves S, Hillen AEJ, et al. Astrocyte subtype vulnerability in stem cell models of vanishing white matter. Ann Neurol. 2019;86(5):780-792.

27. Sidrauski C, McGeachy AM, Ingolia NT, Walter P. The small molecule ISRIB reverses the effects of eIF2a phosphorylation on translation and stress granule assembly. Elife. 2015;4:e05033.

28. Welsh GI, Miller CM, Loughlin AJ, Price NT, Proud CG. Regulation of eukaryotic initiation factor eIF2B: glycogen synthase kinase-3 phosphorylates a conserved serine which undergoes dephosphorylation in response to insulin. FEBS Lett. 1998;421(2): 125-130.

29. Halliday M, Radford H, Zents KAM, et al. Repurposed drugs targeting eIF2 $\alpha$-Pmediated translational repression prevent neurodegeneration in mice. Brain. 2017; 140(6):1768-1783.

30. Keefe MD, Soderholm HE, Shih HY. et al. Vanishing White Matter disease expression of truncated EIF2B5 activates induced stress response. bioRxiv 2020.

31. Jiang HQ, Ren M, Jiang HZ, et al. Guanabenz delays the onset of disease symptoms, extends lifespan, improves motor performance and attenuates motor neuron loss in the SOD1 G93A mouse model of amyotrophic lateral sclerosis. Neuroscience. 2014; 277:132-138.

32. Chen Y, Podojil JR, Kunjamma RB, et al. Sephin1, which prolongs the integrated stress response, is a promising therapeutic for multiple sclerosis. Brain. 2019;142(2): 344-361.

33. Bella ED, Bersano E, Antonini G, et al. The unfolded protein response in amyotrophic later sclerosis: results of a phase 2 trial. Brain. 2021;144(9):2635-2647.

34. Ng N, Castro Cabral-da-Silva M, Maksour S, et al. Identification of repurposable cytoprotective drugs for vanishing white matter disease. bioRxiv. 2020.

35. Atzmon A, Herrero M, Sharet-Eshed R, Gilad Y, Senderowitz H, Elroy-Stein O. Drug screening identifies sigma-1-receptor as a target for the therapy of VWM leukodystrophy Front Mol Neurosci. 2018;11:336.

36. van der Knaap MS, Fogli A, Boespflug-Tanguy O, Abbink TEM, Schiffmann R. Childhood ataxia with central nervous system hypomyelination/Vanishing White Matter. In: Adam MP, Ardinger HH, Pagon RA, et al, eds. GeneReviews. University of Washington, Seattle; 1993-2020 (updated April 4 2019). Available at genetests. org.

37. Schmidt JL, Pizzino A, Nicholl J, et al. Estimating the relative frequency of leukodystrophies and recommendations for carrier screening in the era of next-generation sequencing. Am J Med Genet A. 2020;182(8):1906-1912.

38. Soderholm HE, Chapin AB, Bayrak-Toydemir P, Bonkowsky JL. Elevated leukodystrophy incidence predicted from genomics databases. Pediatr Neurol. 2020;111 66-69.

39. van der Knaap MS, Wevers RA, Kure S, et al. Increased cerebrospinal fluid glycine; a biochemical marker for a leukoencephalopathy with vanishing white matter. J Child Neurol. 1999;14(11):728-731.

40. Vanderver A, Schiffmann R, Timmons M, et al. Decreased asialotransferrin in cerebrospinal fluid of patients with childhood-onset ataxia and CNS hypomyelination/ vanishing white matter disease. Clin Chem. 2005;51(11):2031-2042.

41. Chmielewska N, Szyndler J, Makowska K, Wojtyna D, Maciejak P, Płaźnik A. Looking for novel, brain-derived, peripheral biomarkers of neurological disorders. Neurol Neurochir Pol. 2018;52(3):318-325.

42. Wolf NI, ffrench-Constant C, van der Knaap MS. Hypomyelinating leukodystrophiesunravelling myelin biology. Nat Rev Genet. 2021;17(2):88-103.

43. Delphi Method Software. edelphi.org. 
44. Augustine EF, Adams HR, Mink JW. Clinical trials in rare disease: challenges and opportunities. J Child Neurol. 2013;28(9):1142-1150.

45. Mulberg AE, Bucci-Rechtweg C, Giuliano J, et al. Regulatory strategies for rare diseases under current global regulatory statutes: a discussion with stakeholders. Orphanet J Rare Dis. 2019;14:36.

46. Kempf L, Goldsmith JC. Temple R Challenges of developing and conducting clinical trials in rare disorders. Am J Med Dis. 2018;176(4):773-783.

47. Müller AR, Brands MMMG, van de Ven PM, et al. Systematic review of N-of-1 studies in rare genetic neurodevelopmental disorders. Neurology. 2021;96(11): 529-540.

48. van der Knaap MS, Schiffmann R, Mochel F, Wolf NI. Diagnosis prognosis and treatment of leukodystrophies. Lancet Neurol. 2019;18(10):962-972.

49. I Dali C, Sevin C, Krägeloh-Mann I, et al. Safety of intrathecal delivery of recombinant human arylsulfatase $\mathrm{A}$ in children with metachromatic leukodystrophy: results from a phase 1/2 clinical trial. Mol Genet Metab. 2020;131(1-2):235-244.
50. Rabouw HH, Langereis MA, Anand AA, et al. Small molecule ISRIB suppresses the integrated stress response within a defined window of activation. Proc Natl Acad Sci U $S$ A. 2019;116(6):2097-2102.

51. Schmidt S, Denk S, Wiegering A. Targeting protein synthesis in colorectal cancer. Cancers (Basel). 2020;12(5):1298.

52. Jiao Y, Fu Z, Li Y, Meng L, Liu Y. High EIF2B5 mRNA expression and its prognostic significance in liver cancer: a study based on the TCGA and GEO database. Cancer Manag Res. 2018;10:6003-6014.

53. Viele K, Berry S, Neuenschwander B, et al. Use of historical control data for assessing treatment effects in clinical trials. Pharm Stat. 2014;13(1):41-54.

54. Saville BR, Berry SM. Efficiencies of platform clinical trials: a vision of the future. Clin Trials. 2016;13(3):358-366.

55. Lu CC, Li XN, Broglio K, et al. Practical considerations and recommendations for master protocol framework: basket, umbrella and platform trials. Ther Innov Regul Sci. $2021 ; 55(6): 1145-1154$ 


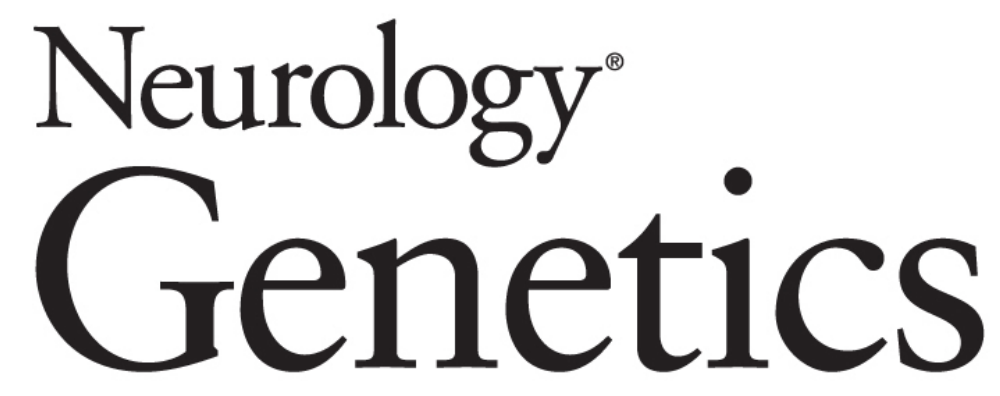

Therapy Trial Design in Vanishing White Matter: An Expert Consortium Opinion Marjo S. van der Knaap, Joshua L. Bonkowsky, Adeline Vanderver, et al. Neurol Genet 2022;8;

DOI 10.1212/NXG.0000000000000657

This information is current as of February 2, 2022

\begin{abstract}
Updated Information \& Services

including high resolution figures, can be found at: http://ng.neurology.org/content/8/2/e657.full.html

References

This article cites 50 articles, 5 of which you can access for free at: http://ng.neurology.org/content/8/2/e657.full.html\#\#ref-list-1

Subspecialty Collections

This article, along with others on similar topics, appears in the following collection(s):

Clinical trials Methodology/study design

http://ng.neurology.org//cgi/collection/clinical_trials_methodology_stu dy_design

Leukodystrophies

http://ng.neurology.org//cgi/collection/leukodystrophies

Permissions \& Licensing its entirety can be found online at:

http://ng.neurology.org/misc/about.xhtml\#permissions

Reprints

Information about ordering reprints can be found online: http://ng.neurology.org/misc/addir.xhtml\#reprintsus
\end{abstract}

Information about reproducing this article in parts (figures,tables) or in

Neurol Genet is an official journal of the American Academy of Neurology. Published since April 2015, it is an open-access, online-only, continuous publication journal. Copyright Copyright $\odot 2022$ The Author(s). Published by Wolters Kluwer Health, Inc. on behalf of the American Academy of Neurology.. All rights reserved. Online ISSN: 2376-7839.

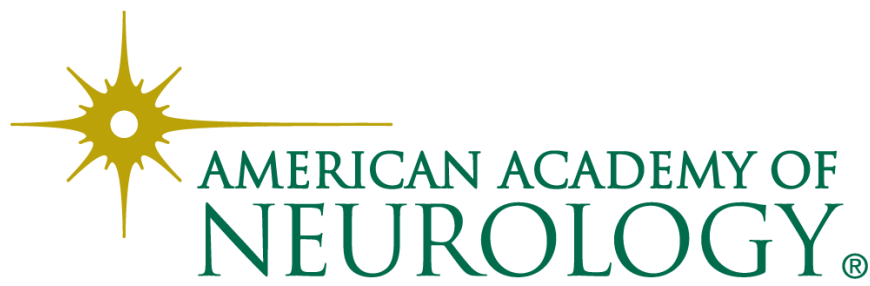

